\title{
New Electron Microscopy Techniques for the Study of Meteoritic Metal
}

\author{
J. I. Goldstein, ${ }^{*}$ J.R. Michael, ${ }^{* *}$ P.G. Kotula, ${ }^{* *}$ and R.H. Jones*** \\ * Mechanical and Industrial Engineering, University of Massachusetts, Amherst, MA 01003 \\ ** Materials Characterization Department, Sandia National Laboratories, PO BOX 5800, MS 0886, \\ Albuquerque, NM 87185 \\ *** Earth and Planetary Sciences, University of New Mexico, Albuquerque, NM 87131
}

Metallic Phases in extraterrestrial materials are composed of Fe-Ni with minor amounts of $\mathrm{Co}, \mathrm{P}, \mathrm{Si}, \mathrm{Cr}$, etc. Electron microscopy techniques (SEM, TEM, EPMA, AEM) have been used for almost 50 years to study micron and submicron microscopic features in the metal phases (Fig. 1) such as clear taenite, cloudy zone, plessite, etc [1,2]. However lack of instrumentation to prepare TEM thin foils in specific sample locations and to obtain micro-scale crystallographic data have limited these investigations. New techniques such as the focused ion beam (FIB) and the electron backscatter electron diffraction (EBSD) techniques have overcome these limitations.

The application of the FIB instrument has allowed us to prepare $\sim 10$ um long by $~ 5 \mathrm{um}$ deep TEM thin sections of metal phases from specific regions of metal particles, in chondrites, irons and stony iron meteorites, identified by optical and SEM observation. Using a FEI dual beam FIB we were able to study very small metal particles in samples of $\mathrm{CH}$ chondrites [3] and zoneless plessite (ZP) in ordinary chondrites. Fig. 2 shows a SEM photomicrograph of a $\sim 40$ um ZP particle in Kernouve, a H6 chondrite. Fig. 3a,b shows a TEM photograph of a section of the FIB prepared TEM foil of the ZP particle and a Ni trace through a tetrataenite/kamacite region of the particle.

It has been proposed that the Widmanstatten pattern in low $\mathrm{P}$ iron meteorites forms by martensite decomposition, via the reaction $\gamma \rightarrow \alpha_{2}+\gamma \rightarrow \alpha+\gamma$ in which $\alpha_{2}$, martensite, decomposes to the equilibrium $\alpha$ and $\gamma$ phases during the cooling process [4]. In order to show if this mechanism for Widmanstatten pattern formation is correct, crystallographic information is needed from the $\gamma$ or taenite phases throughout a given meteorite. The EBSD technique was employed in this study to obtain the orientation of the taenite surrounding the initial martensite phase and the kamacite which forms as $\alpha_{2}$ or as Widmanstatten plates in a series of IVB irons. Fig. 4a,b shows EBSD orientation maps of taenite and kamacite from the Tawallah Valley IVB iron. We observe that the orientation of the taenite in the IVB meteorites is the same throughout the sample consistent with the orientation of the high temperature single phase taenite before formation of the Widmanstatten pattern.

References

[1] C. W. Yang et al., Geochim. Cosmochim. Acta, 61 (1997) 2943.

[2] J. Zhang et al., Geochim. Cosmochim. Acta, 57 (1993) 3725.

[3] J. I. Goldstein et al., Lunar Planet. Sci. XXXV (2005).

[4] J. Yang and J. I. Goldstein, Met. Planet. Sci. (2005) in press.

[6] The financial support from NASA through grants NAG5-11778 and NAG5-9463 are acknowledged. Sandia is a multiprogram laboratory operated by Sandia Corporation, a LockheedMartin Company, for the United States Department of Energy (DOE) under contract DE- 
AC0494AL85000.
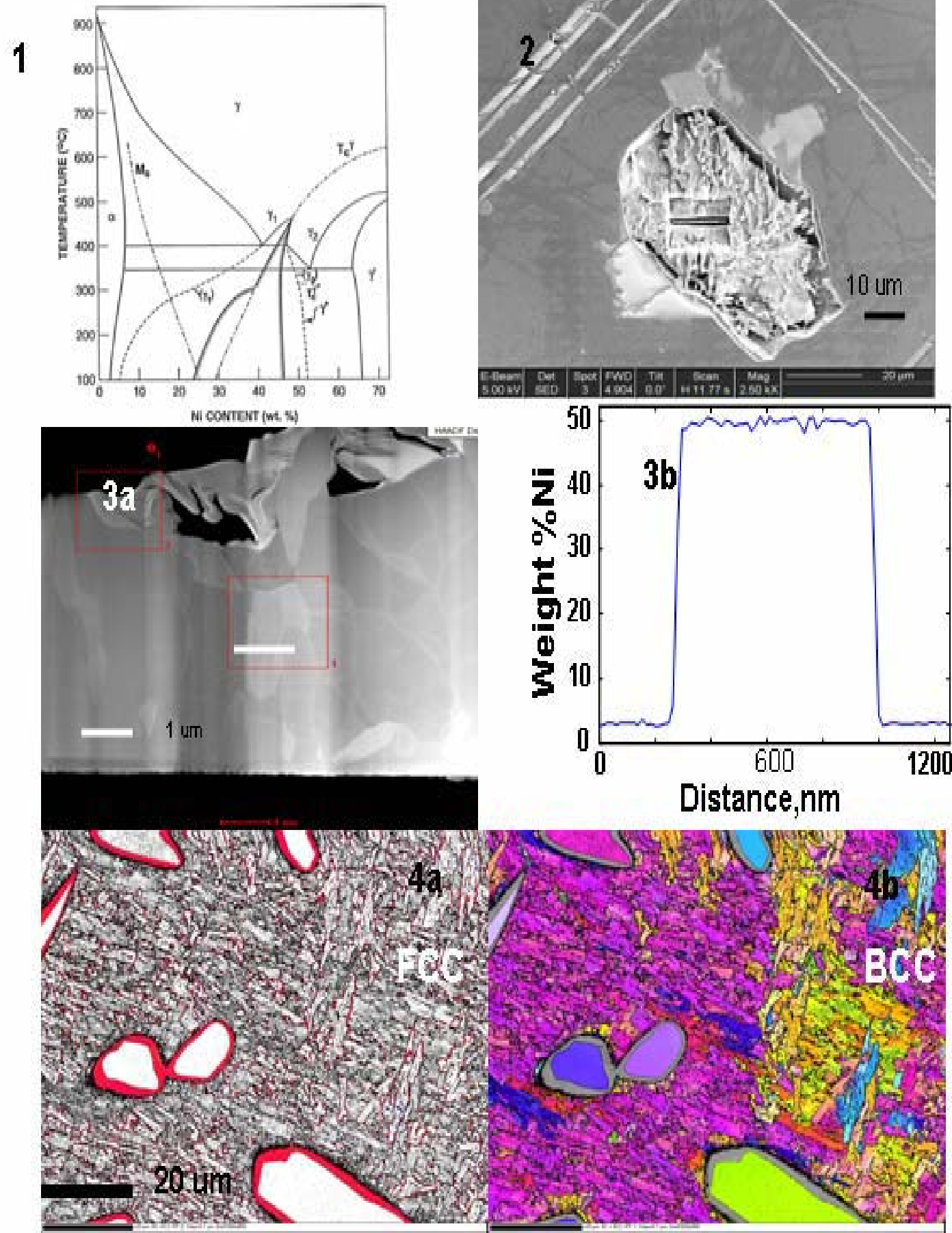

Figure 1 Fe-Ni Phase Diagram

Figure 2 FIB cut in Zoneless Plessite (ZP) region of Kernouve H6 Chondrite

Figure 3a STEM image of FIB section, Kernouve ZP. White bar shows X-ray analysis region, kamacite/ tetrataenite/ kamacite.

Figure $3 \mathrm{~b}$ Ni composition profile across analysis region.

Figure 4 EBSD images of Tawallah Valley IVB iron meteorite. A) FCC B) BCC 